\title{
El impacto de la crisis económica en los tributos y en la sostenibilidad del nuevo modelo social en España. Aproximación desde una perspectiva de género
}

\author{
Paloma DE VILLOTA \\ Profesora Titular de Economía Aplicada. Universidad Complutense de Madrid \\ pvillota@anit.es
}

Recibido: 02.10.2011

Aceptado: 15.11.2011

\section{RESUMEN}

Este artículo analiza el colapso de la recaudación en el año 2008 como consecuencia del colapso del sector inmobiliario poniendo en peligro la sostenibilidad del modelo social existente, tras el esfuerzo fiscal realizado en España desde la Transición Democrática en 1977. Sin embargo, pese al continuado aumento de la presión fiscal durante los últimos treinta años, España solo ha logrado situarse entre aquellos regímenes sociales de la Unión Europea menos desarrollados, como Italia, Grecia o Portugal en los que el cuidado infantil y de mayores dependientes no constituye todavía una prioridad de la política social.

Palabras clave: crisis económica, presión fiscal, cuidado, modelo social,Transición democrática.

\section{The crisis impact on taxation and the social model in Spain. A gender approach}

\begin{abstract}
This article underlines the plummet of public incomes in year 2008 as consequence of the collapse of the building sector and the risk to maintain the Spanish social model that this fact supposed. This model was established since Democratic Transition in year 1977 and has supposed and important increase during last thirty years in the tax burden to be paid by citizens. Even though, Spain has developed a social regime completely underdeveloped, inside European Union, similar to those existing in Italy, Greece and Portugal, countries where social services or public transfers for children or dependants, especially old, it is not yet a priority of their social policy.
\end{abstract}

Key words: economic crisis, tax burden, care, social model

"Conservar el Estado social exige profundas transformaciones en una sociedad tan fragmentada como la que a la vista se está desplegando, pero caben pocas dudas de que permanecerá, si no se produce una caída en picado de la economía” 1

${ }^{1}$ Ignacio Sotelo: El Estado Social. Antecedentes, origen, desarrollo y declive. Editorial Trotta . 2010 


\section{INTRODUCCION}

El modelo social español es semejante al de otros países europeos meridionales como Italia, Portugal y Grecia, de acuerdo con la clasificación realizada por Gauthier (2002), basada en sus políticas familiares. Sin embargo, España durante los últimos años, una tímida apuesta por dejar de contemplar la dependencia de mayores y el cuidado infantil, como meros apéndices de su política social. Por ejemplo, la Ley 39/ 2006, de 14 de diciembre, de Promoción de la Autonomía Personal y Atención a la Dependencia, va a suponer un hito importante al consagrar la atención a la dependencia como un derecho subjetivo y, por otra parte, el aumento continuado en el número de plazas en educación infantil, para menores de tres años, mostraba una idéntica voluntad de cambio. Sin embargo, el esfuerzo económico requerido para este viraje social no parece coincidir con la conciencia fiscal de la ciudadanía, al considerar excesiva la carga fiscal soportada.

Ante esta tesitura, los efectos devastadores de la crisis económica actual, a través de lo que se denomina política fiscal automática o de estabilizadores automáticos, ha generado un brusco hundimiento de la recaudación impositiva, pues solo durante 2008 y 2009 se pierden en ingresos tributarios jsiete puntos porcentuales del Producto Interior Bruto (PIB)! Esta hecatombe, pues no puede denominarse de otra manera, ha marcado su impronta en la vertiente de ingresos de los Presupuestos Públicos que, al mismo tiempo, han visto aumentar sus partidas de gasto, como consecuencia del vertiginoso incremento de las transferencias por desempleo (en el año 2009 suponían el 3’7 \% del PIB). Es fácil colegir la aparición inmediata de un importante déficit público, como consecuencia de estos efectos cruzados, ${ }^{2}$ y el 2009 se va a cerrar con un déficit presupuestario de dos dígitos (11’4\% del Producto Interior Bruto) que no es de extrañar provoque el pánico en el Gobierno y un viraje draconiano en su política económica y social.

Sin duda, las tensiones generadas, tras el colapso financiero de Grecia en la primavera de 2010, los mercados monetarios amenazaron a los llamados países periféricos dentro el conjunto de la Unión Europea, conocidos con el acrónimo despectivo PIGS (Portugal, Irlanda, Grecia y España). Con esta amenaza, las medidas que se han ido tomando en España no han hecho más que ir recortando paulatinamente los derechos sociales consolidados desde en la Transición democrática.

Ahora bien, debe destacarse que solo en años muy recientes el cuidado de personas mayores dependientes se ha configurado como un derecho subjetivo en nuestro ordenamiento jurídico (2.006), aunque el efecto de la crisis económica ha ralen-

\footnotetext{
2 Además de otra posibles causas, en las que no voy a entrar por falta de espacio, entre las que cabría reseñar el Plan E, medida de estímulo aconsejable dentro del modelo Keynesiano y defendido por Paul Krugman en la actualidad, aunque manifiestamente mejorable como ponen de relieve Glorial Alarcón et alter en este número monógráfico.
} 
tizado su implantación que debería finalizar en el 2015.Por otra parte, el esfuerzo por paliar la falta de una adecuada escolarización infantil primaria (menores de tres años) no se ha visto afectado, de la misma manera, por la permanencia del Plan Educa3, con 100 millones de euros anuales, incluso en el 2011, para apoyar esta política escolar en las Comunidades Autónomas, incluso en el caso que éstas no pudieran aportar efectivo alguno.

Después de esta breve reseña introductoria, quiero subrayar que el objetivo primordial de estas páginas es, en primer lugar, hacer hincapié en el esfuerzo colectivo efectuado durante la Transición democrática, a través de la Reforma Fiscal con el objetivo de conseguir una recaudación tributaria más acorde con los países de nuestro entorno, tanto de la Unión Europea como de la OCDE. La importancia de lograr una recaudación tributaria suficiente debe entenderse como requisito indispensable para desarrollar una política social democrática y acorde con los demás países europeos. No en vano, la Constitución de 1978 consagra la solidaridad fiscal de la ciudadanía al exigir que cada cual contribuya al mantenimiento de las cargas del sector público "de acuerdo con su capacidad económica".

Este artículo se divide en dos apartados netamente diferenciados, en la primera parte se analiza la evolución de la presión fiscal desde la Transición democrática hasta el impacto de la crisis económica actual, con el derrumbe impositivo padecido y retroceso en el camino andado desde entonces; en el segundo apartado se pone de relieve el modelo social construido durante estos años, similar al de otros países del sur de Europa, como Italia, Portugal y Grecia, y se señalan los intentos de mejora de los últimos años, con la inclusión del cuidado de las personas dependientes como un derecho subjetivo y la ampliación paulatina de la cobertura escolar infantil. En ambas partes subrayo cómo el impacto de la crisis económica actual, con el colapso de la recaudación tributaria, puede truncar la supervivencia de nuestro modelo social, por haberse iniciado desde 2010 una peligrosa y difícil etapa de retroceso, por el continuo recorte de los derechos sociales.

\section{EVOLUCIÓN DE LA PRESIÓN FISCAL EN ESPAÑA}

El índice más utilizado para medir el esfuerzo fiscal realizado por quienes contribuyen en un país o región al sostenimiento de las cargas públicas es el denominado índice de presión fiscal, definido por la relación entre la recaudación proporcionada por el conjunto de los impuestos y el PIB. En las comparaciones internacionales se incluyen las cotizaciones a la seguridad social pues forman parte de los ingresos coactivos del Estado y, por tanto, son considerados como impuestos, criterio seguido en el desarrollo de este apartado. En definitiva, este índice permite obtener una idea de la importancia relativa o peso del sector público en el conjunto de la economía del país o región considerada. 
Según los datos proporcionados por la Organización para la Cooperación y el Desarrollo Económico (OCDE), que agrupa a los países con economías más desarrollados del planeta, la presión fiscal en 2010 oscilaba entre el máximo de Dinamarca, con 48,2\%, y el mínimo de Méjico, con 18,1\%, lo que permite percibir la gran dispersión existente. A la cabeza se encuentran los países nórdicos junto con Bélgica, Italia y Francia. En el extremo opuesto se sitúan Méjico, Chile y EEUU, con índices inferiores al 25\%. Por su parte, España se encuadra, en 2010, dentro de los países con presión fiscal media pues alcanzaba 31,7\% despues de una fuerte reducción en el período 2007 a 2010, como se verá más adelante (en el anexo se ofrece la evolución de la presión fiscal de los distintos miembros de la OCDE).

Presión fiscal en los países miembros de la OCDE, 2010

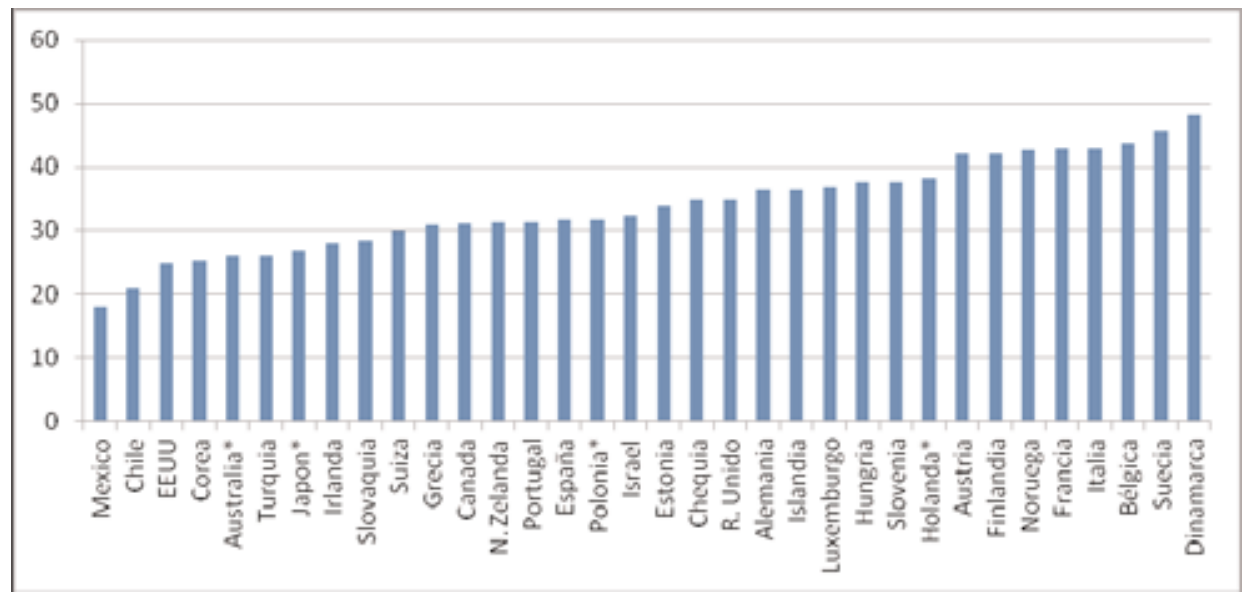

(*) Datos de 2009

(Fuente: OECD Revenue Statistics 1965-2010. Paris 2011)

Si se observa el gráfico anterior, se puede inferir cierta relación entre la presión fiscal de los países miembros de la OCDE y el grado de protección social de sus políticas públicas de bienestar así como su encuadre en la tipología desarrollada por Gosta Sping-Andersen (1990), como es el caso de Dinamarca, Suecia, Noruega y Finlandia. Los países de corte "liberal", como EEUU, Australia, etc., con escasa presencia de la política pública en la provisión de protección social y, en donde cada persona debe al menos complementarla de forma individual y/o privada, muestran una baja presión fiscal en comparación con el resto. Los países considerandos como "continentales" o "corporativos", representados, entre otros por Alemania o Austria, en los que los derechos sociales están ligados a la permanencia en el mercado laboral o a los recibidos en concepto de derechos derivados, es decir por su vínculo legal con la persona que trabaja de forma remunerada (recibiendo por ello pensiones de orfandad, viudedad, etc.) pero en los que pueden coe- 
xistir algunos derechos universales como a la sanidad a la educación. Estos países suelen tener una presión fiscal media. En tercer lugar, los regímenes "socialdemócratas" (Suecia, Dinamarca, Noruega y Finlandia) en los que están implantados derechos universales de ciudadanía con acceso geuniversal a la sanidad, educación, pensiones de vejez, etc. presentan una mayor presión fiscal, próxima al 50\% del PIB. Solo los movimientos migratorios de los últimos años han cuestionado sus logros sociales (Borshorst, 2011). España y Portugal, que se podrían considerar encuadrados dentro del modelo Mediterráneo de bienestar (Rodríguez Cabrero, 1991), en el que la familia sigue ejerciendo un papel destacado para la consecución del bienestar social (cuidado infantil, de personas mayores y familiares enfermos), presentan un nivel de presión fiscal inferior aunque no muy diferente a la de algunos países “continentales" o "corporativos". El caso de Italia requiere un análisis en mayor profundidad pues su elevada presión fiscal no corresponde a la tipología en la que se encuandra (modelo Mediterráneo); ello puede deberse al elevado coste del servicio de su deuda soberana que ha llegado a superar su producción interior, alcanzando el 120\% del PIB. A pesar de que España se encuentre entre los países con una presión fiscal media, el grado de provisión de protección social para el cuidado infantil, por ejemplo, es inferior, como se verá en el apartado siguiente, respecto a otros países que presentan un análogo esfuerzo fiscal (Reino Unido, Luxemburgo, etc.).

\subsection{EVOLUCIÓN DESDE LA TRANSICIÓN}

Tras salir de la dictadura franquista en 1975, España acometió una reforma fiscal en profundidad para equipararnos al resto de los países de nuestro entorno económico. La Ley 50/1977, de 14 de noviembre, sobre medidas urgentes de reforma fiscal, marca el punto de partida de la reforma instaurando el delito fiscal, el secreto bancario, el Impuesto Extraordinario sobre el Patrimonio, a la vez que se otorgó una amnistía fiscal. Un conjunto de leyes posteriores completarán el actual sistema tributario y la reforma impositiva se cerrará con la introducción del Impuesto sobre el Valor Añadido el primero de enero de 1986 coincidiendo con nuestro ingreso en la Unión Europea.

Con el desarrollo de la reforma tributaria la presión fiscal aumentó de forma espectacular, pasando del 17,1\% en 1974 al 26,4\% en 1984, siendo el país que mayor esfuerzo fiscal llevo a cabo durante ese período, como queda reflejado en el gráfico adjunto: 
Variación de la presión fiscal en los países de la OCDE durante el período 1975-1985

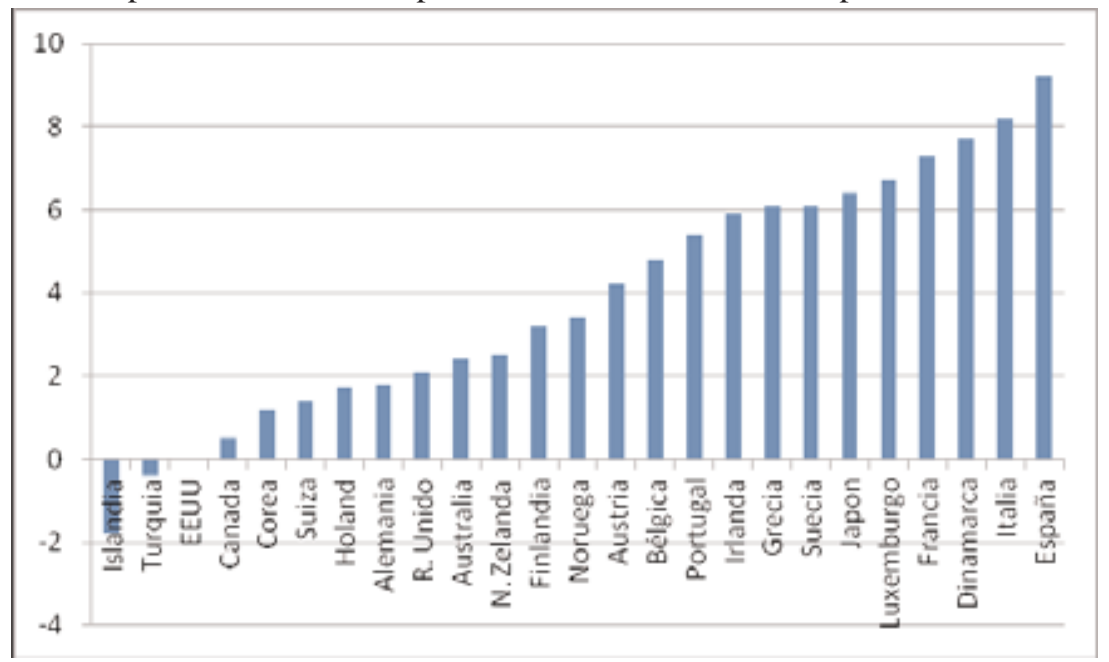

(Fuente: OECD Revenue Statistics 1965-2007. Paris 2008)

De 1975 a 1985, la mayoría de los países aumentaron significativamente su presión fiscal (diez de los cuales superaron un crecimiento de cinco puntos porcentuales) aunque España se colocó a la cabeza, seguido de Italia. Por el contrario dos países -Turquia e Islandia- la redujeron y solo uno de ellos, Estados Unidos, prácticamente no presentó variación alguna.

Durante los diez años siguientes, 1985 a 1995, España siguió aumentando su presión fiscal, con un crecimiento cercano a los cinco puntos porcentuales, de tal forma que en 1995 alcanzó el 32,1\%; por lo que en este período se situará en el grupo de cabeza siendo el sexto en crecimiento recaudatorio, como muestra el gráfico siguiente:

Variación de la presión fiscal en los países de la OCDE durante el período 1985-1995

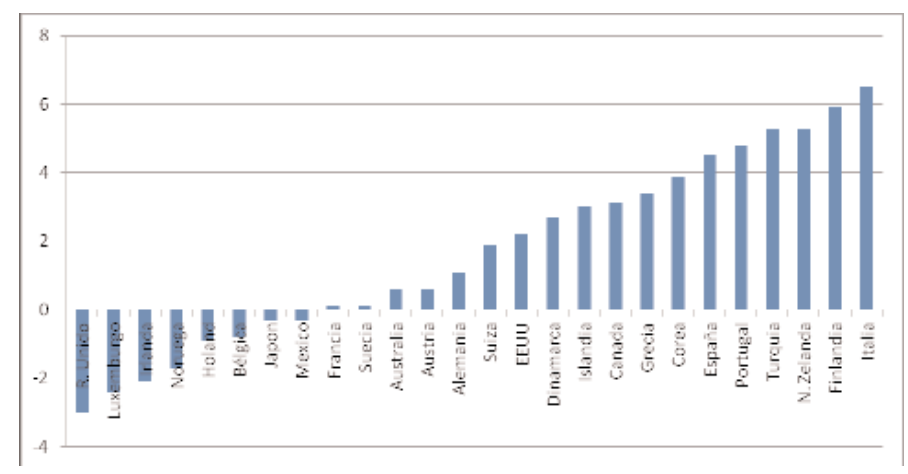

(Fuente: OECD Revenue Statistics 1965-2007. Paris 2008) 
Durante este periodo destaca el retroceso de tres puntos porcentuales con relación al PIB de Gran Bretaña, como consecuencia inmediata del impacto neoliberal del programa de Thatcher y el escaso crecimiento de los países nórdicos, a excepción de Finlandia, por no mencionar el retroceso de Noruega que redujo su presión fiscal cerca de dos puntos. La crisis económica del primero como consecuencia del giro de su economía y el petróleo en el caso noruego, además del avance del neoliberalismo económico, repercutieron en sus sistemas tributarios reduciendo fuertemente el esfuerzo fiscal. Pero esta influencia no fue exclusiva de los escandinavos pues otros ocho países más aminoraron también el peso de sus tributos en el conjunto de la economía, e incluso algunos de manera significativa como Holanda, Irlanda, Luxemburgo, etc.

En los once años siguientes, 1995-2006, quince países ${ }^{3}$ verán disminuir su presión fiscal y en mayor proporción (tasas mayores) que lo hicieron en el período anterior, como muestra el gráfico expuesto a continuación. En España, a pesar de la promesa de Aznar de reducir los impuestos durante su mandato, el esfuerzo fiscal ha seguido aumentando, al igual que en Corea, Turquía e Islandia. No obstante, se perfila nítidamente en el conjunto de países el impacto creciente de la teoría económica neoliberal que postula la paulatina reducción del tamaño del sector público con el retroceso de la presión fiscal.

Variación de la presión fiscal en los países de la OCDE durante el período 1995-2007

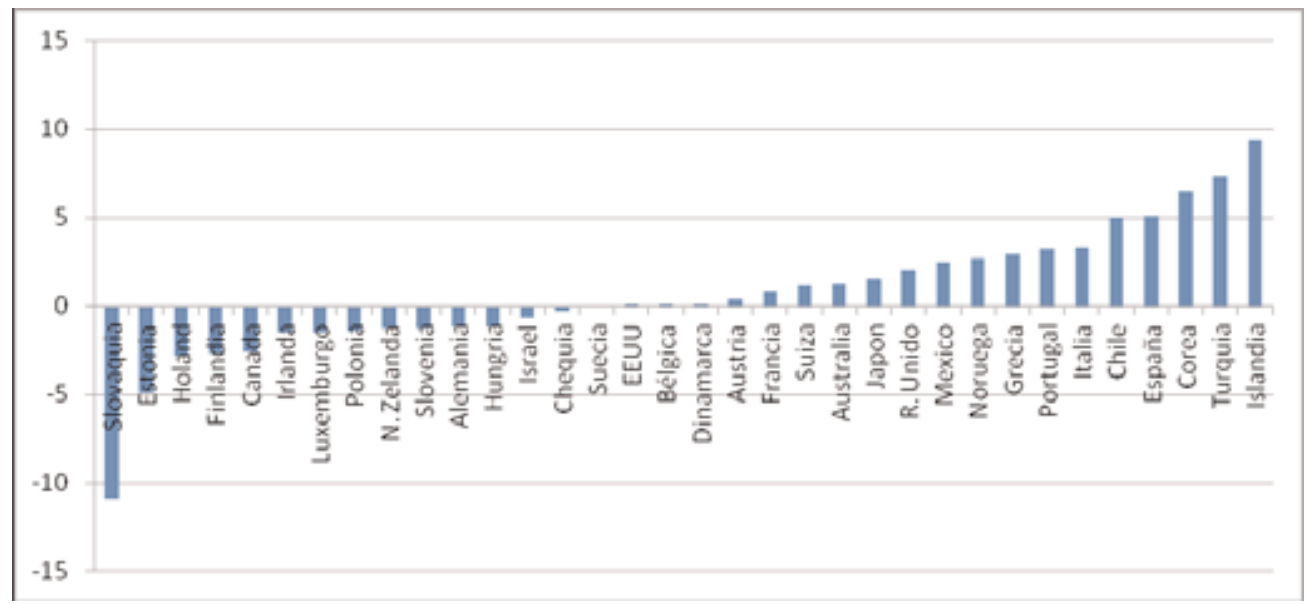

(Fuente: OECD Revenue Statistics 1965-2010. Paris 2011)

3 Durante este periodo se han incorporado nuevos miembros en la OCDE. 
Por tanto, en este somero análisis se pone de manifiesto que España es el país que más ha incrementado su presión fiscal durante el período 1975 a 2007, como muestra el cuadro incluido en el anexo documental. Este hecho podría explicar la falsa percepción, bastante generalizada, que considera a España como un país en el que se pagan excesivos impuestos en comparación con otros Estados miembros de la UE o de la OCDE. Esta percepción queda recogida de forma palmaria en la encuesta “Opinión Publica y Política Fiscal, XXVI" realizada en 2009 por el Centro de Investigaciones Sociológicas (CISS) en donde el 58\% de las españolas y el 46\% de los españoles consideran que los impuestos son "muy elevados"; el 30\% de las españolas y el $43 \%$ de los españoles "elevados" y menos del $1 \%$ del total "reducidos". El incremento de 18,8 puntos porcentuales de la presión fiscal de 1975 a 2007 solo es comparable con lo ocurrido en Italia, Portugal y Grecia, países con regímenes sociales de bienestar similares.

Por otra parte, la estructura de la escala de tributo y la magnitud de los tipos marginales constituyen dos parámetros de gran trascendencia a la hora de fijar una mayor o menor progresividad en la imposición personal sobre la renta. Pero, durante las últimas décadas, el intento de no penalizar el ahorro en aras de un mayor crecimiento económico ha sido el leitmotiv de la tributación en casi todos los países. Y ello ha generado importantes cambios en el sistema tributario que han avocado a un descenso de la presión fiscal directa y un aumento de la indirecta, más que a un descenso real en el nivel de la presión fiscal.

Estos cambios han provocado una aminoración de la progresividad impositiva en la imposición sobre la renta, desde la década de los noventa. Debido, en primer lugar, a una reducción generalizada de la imposición sobre el capital y, en segundo término, a la rebaja de los tipos marginales más altos en las rentas laborales que generan un impacto diferenciado en las mujeres y en los hombres, debido a su diferente situación socioeconómica en el mercado de trabajo (Villota, 2010).

Sin embargo, el impacto inmediato de la crisis en España ha supuesto una pérdida de recaudación impositiva muy superior a la detectada en otros países de nuestro entorno, y este impacto fiscal puede poner en riesgo la continuidad de nuestro modelo social por la falta de recursos económicos y la aparición de un déficit presupuestario de dos dígitos en el año 2009 (11,4\% del PIB). 
Variación de la presión fiscal en los países de la OCDE durante el período 2007-2009

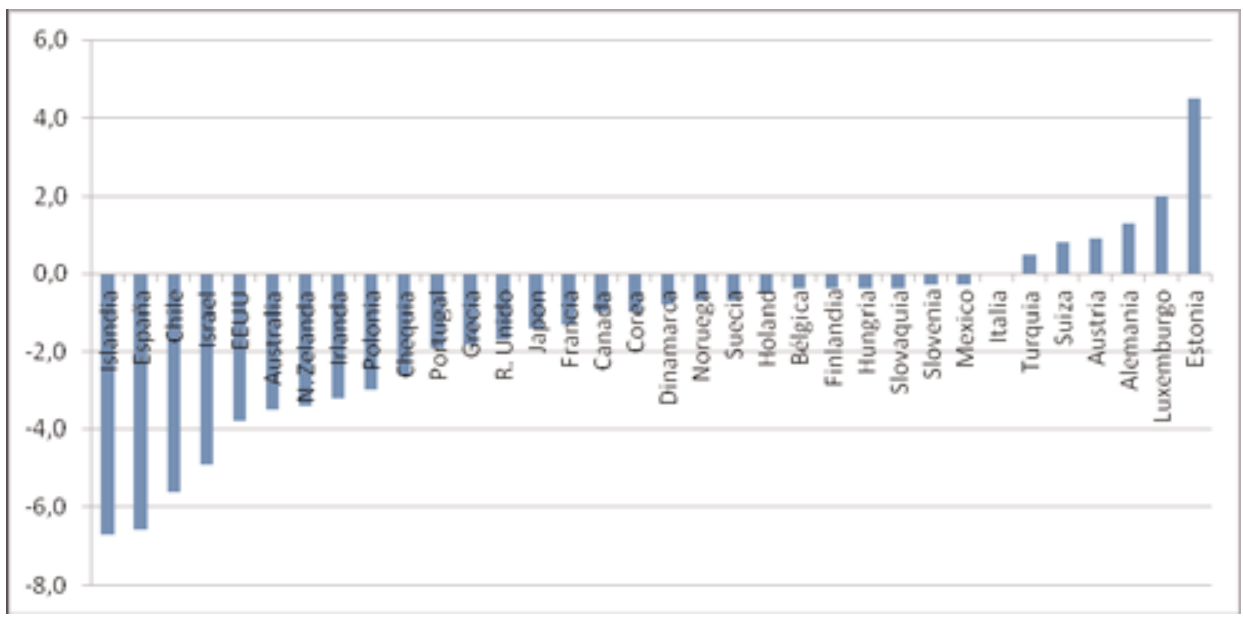

(Fuente: OECD Revenue Statistics 1965-2010. Paris 2011)

\section{INTERRELACIÓN ENTRE LA PRESIÓN FISCAL Y DISEÑO DE LA POLÍTICA SOCIAL CON ESPECIAL REFERENCIA AL GASTO SOCIAL EN CUIDADO Y EDUCACIÓN INFANTIL}

En este segundo apartado se comparan los datos del gasto social en transferencias y servicios públicos en diferentes países en Europa. Su cuantía refleja el coste de los servicios sociales, como desempleo, pensiones de supervivencia o jubilación, salud, discapacidad, atención a las familias para el cuidado infantil, viviendas sociales y exclusión social. Se incluyen también los costes administrativos de su gestión y otros gastos de diversa naturaleza.

Y su evolución desde 2000 en proporción al Producto Interior Bruto se desglosa a continuación para diferentes países europeos 
Gasto en protección social como \% del PIB

\begin{tabular}{|c|c|c|c|c|c|c|c|c|c|c|}
\hline & $\underline{2000}$ & $\underline{2001}$ & $\underline{2002}$ & $\underline{2003}$ & $\underline{2004}$ & $\underline{2005}$ & $\underline{2006}$ & $\underline{2007}$ & $\underline{2008}$ & 2009 \\
\hline U27 & : & : & : & : & : & 27,1 & 26,6 & 25,7 & 26,7 & 29,5 \\
\hline U15 & 26,8 & 27,0 & 27,2 & 27,6 & 27,6 & 27,6 & 27,2 & 26,4 & 27,5 & 30,3 \\
\hline élgica & 25,4 & 26,3 & 26,7 & 27,4 & 27,4 & 27,3 & 27,1 & 26,8 & 28,1 & 30,4 \\
\hline Dinamarca & 28,9 & 29,2 & 29,7 & 30,9 & 30,7 & 30,2 & 29,2 & 28,8 & 29,6 & 33,4 \\
\hline Alemania & 29,6 & 29,7 & 30,3 & 30,7 & 30,1 & 30,0 & 28,9 & 27,8 & 28,0 & 31,4 \\
\hline rlanda & 13,8 & 14,7 & 17,0 & 17,7 & 17,9 & 17,9 & 18,2 & 18,8 & 22,0 & 27,9 \\
\hline recia & 23,5 & 24,3 & 24,0 & 23,5 & 23,6 & 24,9 & 24,7 & 24,8 & 26,3 & 28,0 \\
\hline España & 20,0 & 19,7 & 20,0 & 20,3 & 20,3 & 20,6 & 20,5 & 20,7 & 22,1 & 25,0 \\
\hline rancia & 29,5 & 29,6 & 30,5 & 31,0 & 31,4 & 31,5 & 30,9 & 30,6 & 31,0 & 33,1 \\
\hline talia & 24,7 & 24,9 & 25,3 & 25,8 & 26,0 & 26,4 & 26,6 & 26,7 & 27,8 & 29,8 \\
\hline Luxemburgo & 19,6 & 20,9 & 21,6 & 22,1 & 22,3 & 21,7 & 20,4 & 19,3 & 20,2 & 23,1 \\
\hline Holanda & 26,4 & 26,5 & 27,6 & 28,3 & 28,3 & 27,9 & 28,8 & 28,3 & 28,5 & 31,6 \\
\hline Austria & 28,3 & 28,6 & 29,0 & 29,4 & 29,1 & 28,7 & 28,2 & 27,8 & 28,4 & 30,8 \\
\hline Portugal & 20,9 & 21,9 & 22,9 & 23,3 & 23,9 & 24,6 & 24,6 & 23,9 & 24,3 & 26,9 \\
\hline Finlandia & 25,1 & 25,0 & 25,7 & 26,6 & 26,7 & 26,7 & 26,4 & 25,4 & 26,2 & 30,3 \\
\hline Suecia & 29,9 & 30,4 & 31,3 & 32,2 & 31,6 & 31,1 & 30,4 & 29,2 & 29,5 & 32,1 \\
\hline Reino Uni & 26,4 & 26,8 & 25,7 & 25,7 & 25,9 & 26,3 & 26,0 & 23,3 & 26,3 & 29,2 \\
\hline Noruega & 24,4 & 25,4 & 26,0 & 27,2 & 25,9 & 23,8 & 22,6 & 22,9 & 22,5 & 26,4 \\
\hline Suiza & 27,0 & 27,7 & 28,5 & 29,2 & 29,3 & 29,3 & 28,0 & 27,3 & 26,4 & \\
\hline
\end{tabular}

(Fuente: Eurostat, Living Conditions in Europe)

Si se comparan las cifras correspondientes a la columna del año 2007 con las ofrecidas por la presión fiscal de diferentes países se puede vislumbrar, a través de su representación gráfica, la existencia de una correlación entre el nivel de gasto público en protección social y de presión fiscal a escala europea:

Presión fiscal y gasto social (como \% PIB)

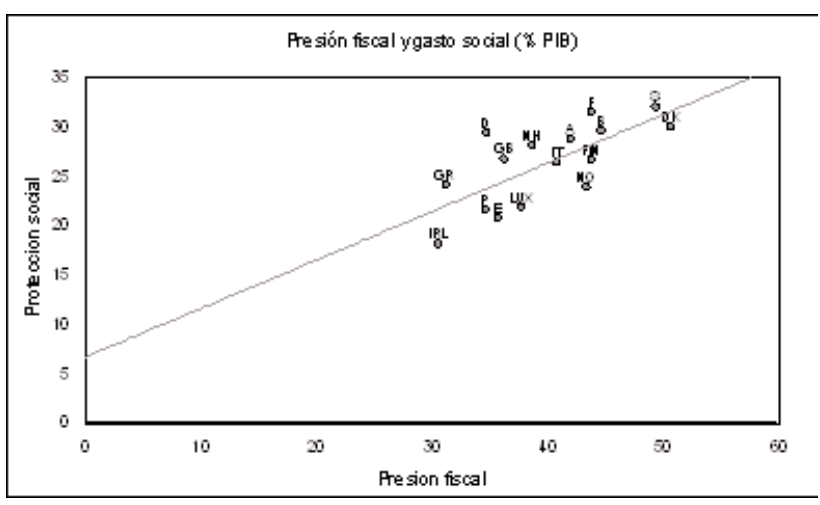

(Fuente: elaboración propia a partir de EUROSTAT Living Conditions in Europe y OECD Revenue Statistics 1965-2010) 
Con este coeficiente de correlación obtenido $(0,713176)$ se aprecia la existencia de una estrecha interrelación entre ambas variables. Por ello, con anterioridad al estallido de la crisis y su impacto en la pérdida de recaudación, se puede considerar que España contaba con recursos suficientes para desarrollar un modelo social Mediterráneo con baja presión fiscal y escasos servicios públicos de atención o cuidado de las personas a lo largo del ciclo vital. Digo escasos servicios públicos, porque ni la educación infantil de menores de tres años o el cuidado de personas mayores dependientes constituía una prioridad fundamental de su política social, aunque estos servicios y prestaciones configuran la idiosincrasia del modelo nórdico de Estado de Bienestar, al igual que la pensión universal de vejez, pero es incuestionable que su dotación requiere una importante cuantía de ingresos públicos.

España, dentro del modelo de Bienestar del sur de Europa, semejante al de Grecia, Italia y Portugal que se caracteriza, de acuerdo con Ferrera (1995), "por un modo peculiar de funcionamiento político que le distingue no solo de los más homogéneos, uniformes y universalistas Estados del Bienestar del norte, sino también de los más fragmentados y corporativos sistemas continentales" mantiene una importante carga de trabajo de cuidado no remunerado en el ámbito familiar (en el que la educación universal se encuadra desde la edad legal de escolarización y no desde el primer día o primer año de de vida; igualmente, el cuidado a la dependencia se ha constituido como un derecho subjetivo, pero solo desde hace muy poco tiempo (desde el año 2006) y el desarrollo legislativo paulatino de la Ley para la Autonomía Personal y Apoyo a la Dependencia se estableció con un dilatado horizonte temporal hasta el 2015, pero la crisis ha ralentizado este proceso. Por consiguiente, dentro del modelo de Bienestar del Sur es difícil imaginar el paso hacia otro tipo de modelo social más universalista, como el Nórdico en el que el cuidado constituye una base fundamental del Estado de Bienestar, y que por ello, se puede considerar más adecuado e, incluso, "amigable" desde una perspectiva de género (Borshorst, 2011).

Si se desglosan las funciones del gasto social para el año 2007 nos encontramos con raquíticas aportaciones desde el sector público en concepto de atención infantil y discapacidad o dependencia si se comparan los desembolsos por estos conceptos de Dinamarca, Suecia, Noruega y Finlandia, como muestra el cuadro adjunto: 


\begin{tabular}{|c|c|c|c|c|c|c|c|c|c|}
\hline & Total & Salud & $\frac{\text { Droca- }}{\text { pacidad }}$ & $\frac{\text { suvina- }}{\underline{\text { ción }}}$ & $\begin{array}{c}y \\
\text { superv }\end{array}$ & $\frac{1 \text { cunu }}{\text { hijos }}$ & $\frac{\text { pleo }}{\text { pleor }}$ & Vivienda & Exclusión \\
\hline EU27 & $\overline{24,7}$ & 7,3 & 2,1 & $\overline{9,6}$ & 1,5 & $\overline{2,0}$ & 1,2 & 0,5 & 0,3 \\
\hline EU15 & 25,3 & 7,6 & 2,1 & 9,8 & 1,6 & 2,1 & 1,3 & 0,5 & 0,4 \\
\hline Bélgica & 25,4 & 7,3 & 1,8 & 8,2 & 2,0 & 2,1 & 3,3 & 0,1 & 0,7 \\
\hline Dinamarca & 28,0 & 6,4 & 4,2 & 10,7 & 0,0 & 3,7 & 1,6 & 0,7 & 0,7 \\
\hline Alemania & 26,7 & 8,0 & 2,2 & 9,3 & 2,1 & 2,8 & 1,5 & 0,6 & 0,2 \\
\hline Irlanda & 17,5 & 7,2 & 1,0 & 3,9 & 0,8 & 2,6 & 1,4 & 0,3 & 0,4 \\
\hline Grecia & 24,2 & 6,8 & 1,2 & 10,5 & 2,0 & 1,5 & 1,1 & 0,5 & 0,6 \\
\hline España & 20,2 & 6,4 & 1,5 & 6,5 & 1,9 & 1,3 & 2,1 & 0,2 & 0,3 \\
\hline Francia & 29,2 & 8,7 & 1,8 & 11,3 & 1,9 & 2,5 & 1,8 & 0,8 & 0,5 \\
\hline Italia & 25,5 & 6,6 & 1,5 & 13,1 & 2,4 & 1,2 & 0,5 & 0,0 & 0,1 \\
\hline Luxemburgo & 19,0 & 4,9 & 2,3 & 5,2 & 1,9 & 3,1 & 0,9 & 0,1 & 0,4 \\
\hline Holanda & 26,7 & 8,6 & 2,4 & 9,6 & 1,2 & 1,6 & 1,1 & 0,4 & 1,7 \\
\hline Austria & 26,9 & 7,0 & 2,2 & 11,3 & 1,9 & 2,7 & 1,4 & 0,1 & 0,3 \\
\hline Portugal & 22,6 & 6,4 & 2,3 & 9,7 & 1,6 & 1,2 & 1,1 & 0,0 & 0,3 \\
\hline Finlandia & 24,6 & 6,5 & 3,1 & 8,6 & 0,9 & 2,9 & 1,9 & 0,2 & 0,5 \\
\hline Suecia & 28,6 & 7,5 & 4,4 & 11,1 & 0,6 & 2,9 & 1,1 & 0,5 & 0,6 \\
\hline Reino Unido & 22,3 & 7,6 & 2,5 & 8,5 & 0,2 & 1,6 & 0,5 & 1,2 & 0,2 \\
\hline Noruega & 22,4 & 7,3 & 4,2 & 6,8 & 0,3 & 2,8 & 0,3 & 0,1 & 0,6 \\
\hline Suiza & 25,4 & 6,7 & 3,1 & 11,6 & 1,1 & 1,2 & 0,8 & 0,1 & 0,7 \\
\hline
\end{tabular}

Fuente: EUROSTAT Living Conditions in Europe, 2012.

El todavía precario e insuficiente desarrollo del modelo social español que, de alguna manera, podría considerarse como una obra inacabada (Villota y Vázquez, 2009), ha sufrido un golpe brutal como consecuencia de la pérdida de recaudación observada en España en el año 2008 y 2009. Ningún país de la OCDE ni de la zona euro ha sufrido un descalabro similar salvo Islandia que también tuvo que soportar la embestida de la crisis en su recaudación fiscal (país en el que se han exigido responsabilidades penales por actuaciones irresponsables en el sector financiero).

Con este hundimiento de la recaudación tributaria, es necesario plantearse el modelo social que deseamos en el futuro y desde el horizonte temporal de principios del año 2012 pues conforme al nivel de nuestra presión fiscal nos podríamos estar aproximando al modelo estadounidense en el que su población carece de cobertura sanitaria universal. Pero además, en España se produce el agravante causado por la incorporación, durante los últimos años, de algunos servicios y prestaciones sociales de cuidado que requieren un mayor esfuerzo fiscal que la ciudadanía no parece aceptar, si se considera la opinión pública tanto por parte de las mujeres como de los hombres, como se vio anteriormente. 


\section{EL CUIDADO Y LA EDUCACIONN INFANTIL}

Dada la imposibilidad de abordar todas las funciones sociales, voy a centrar mi atención en este apartado en la educación infantil que se recibe durante los primeros años de la vida, que presenta diferentes modalidades en la UE.

Si se consideran los diferentes regímenes de cuidado infantil y de personas mayores en Europa, de acuerdo con la clasificación de Bettio y Plantenga (2004), a partir de una gran variedad de modalidades entre las que se incluye la mayor o menor incidencia del cuidado informal, que engloba el cuidado familiar (realizado por miembros de la propia familia, padres, abuelos, parientes, et.), el nivel de desarrollo de la política social en la concesión de permisos parentales y el nivel de provisión de servicios públicos. A partir de estas variables se construye un índice cuya valoración va a oscilar entre una triple clasificación; alta, media y baja. En el caso del cuidado y atención de personas mayores, se construye un índice similar pero a partir del gasto desembolsado en pensiones públicas y grado de cobertura en residencias.

Partiendo de esta metodología se puede apreciar que el cuidado informal infantil, es decir todo lo que no es formal, muestra escasa relevancia en Dinamarca, Finlandia y Francia; media en Alemania, Austria, e Irlanda y alta en los restantes países. Resalta, igualmente, la baja provisión generalizada de servicios "formales" para menores de tres años salvo en Bélgica, Francia, Finlandia, Suecia y Dinamarca y la alta provisión financiera existente en Bélgica y Francia.

La clasificación anterior es contundente y sitúa a España en una posición baja en todos los índices salvo en el del cuidado informal que englobaría toda la actividad de cuidado no remunerado llevada a cabo en el ámbito familiar. Por consiguiente, partimos de una situación de desventaja en cuanto a actuación política se refiere, solo comparable con la existente en Grecia; hay que tener en cuenta que Italia presenta una evaluación media en el indicador referido a permisos parentales y Portugal media en el indicador de provisión financiera (transferencias económicas).

Además, cabe señalar que considerando desde la vertiente impositiva, las deducciones fiscales por niños son dignas de destacar como forma de llevar a cabo el cuidado infantil a través de la política impositiva que rebaja la carga fiscal para las personas con descendientes. Los países que en Europa apuestan en mayor medida por las deducciones fiscales en el ámbito del cuidado infantil son Holanda, Alemania, Francia y Bélgica y en el ámbito de la OCDE Estado Unidos y Canadá como veremos más adelante.

Por consiguiente, hay que tener en consideración que existe un importante debate sobre la forma de llevar a cabo la política familiar y, fundamentalmente entre quienes apuestan, desde una ideología conservadora, por fortalecer el ámbito familiar y el mercado; y quienes, desde una perspectiva socialdemócrata, defienden otro modelo social más desarrollado, implantado desde mediados del siglo pasado en los países 
nórdicos (Esping Andersen, 1993), con el cuidado como parte integrante del mismo (Lewis, 2003). Sin embargo, existen autoras que no consideran esta ambivalencia y defienden los servicios sociales públicos tanto por contar con un mayor nivel de cualificación y especialización, como por reforzar la solidaridad familiar (Knin, 2004).

En el gráfico incluido a continuación se puede apreciar las diferentes políticas públicas llevadas a cabo en los países de la OCDE. Esta diversificación presenta perfiles cuantitativos diversos, además de los cualitativos no visibles en la representación. El gráfico, para el año 2007, muestra en la altura de sus barras la importancia cuantitativa de estas aportaciones, mientras los colores (rojo, azul y blanco) indican el distinto uso otorgado a los fondos públicos a través de servicios sociales o transferencias, también pueden indicar la pérdida de recaudación o reducción de la deuda tributaria para las personas que tienen niños y niñas a su cargo. Los servicios sociales se corresponde con las áreas azules de las diferentes barras de gasto público con relación al PIB; las rojas a las transferencias monetarias libres o condicionadas; y, la blancas enmarcarían el ámbito de la política fiscal impositiva con las deducciones fiscales o beneficios fiscales otorgados por cuidado infantil.

Debe destacarse que los países de la OCDE gastan en concepto de cuidado infantil una media del 2'3 \% del PIB, si bien se perfilan grandes diferencias cuantitativas entre ellos. Es posible apreciar que la mayoría de los países gastan más en transferencias en lugar de servicios sociales y beneficios fiscales, mientras estos últimos son más relevantes en Alemania, Japón Holanda y Estados Unidos. El gráfico, incluido a continuación, corresponde a datos del año 2007, y permite apreciar sendas diferencias en el gasto público total en ayuda familiar tanto en servicios sociales como transferencias y gastos o beneficios fiscales con respecto al Producto Interior Bruto.

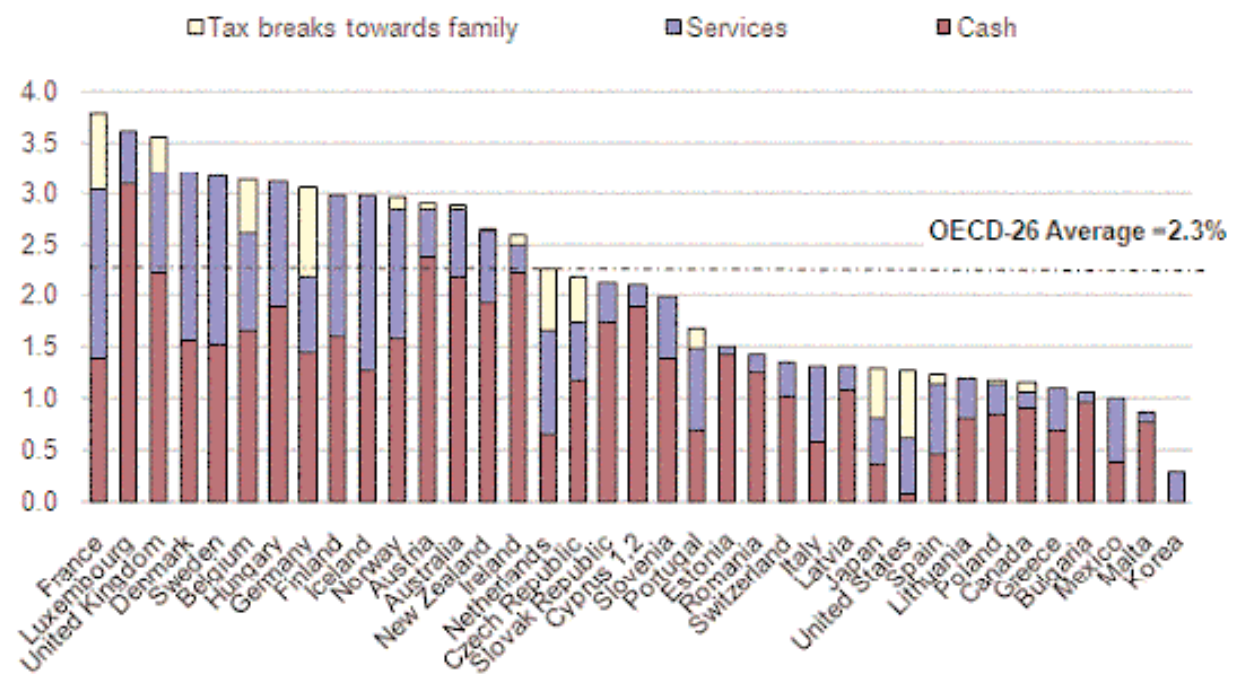


Debe subrayarse que el gasto público en atención infantil incluye:

1. Transferencias, que en ocasiones no tienen carácter universal, por lo que suelen depender, según los distintos países, de la edad de los niños y niñas o del nivel de renta; se incluyen, igualmente, el pago de los permisos parentales y las transferencias existentes para familias monoparentales.

2. Servicios sociales que incluyen los gastos ocasionados en guarderías y educación infantil de carácter público (o parcialmente subsidiado) y otros servicios, entre los que cabe considerar la ayuda domiciliaria para la atención infantil.

3. Beneficios o gastos fiscales que contabiliza las exenciones fiscales a favor de los niños/as e incluyen las transferencias exentas de impuestos; reducciones de la base imponible; deducciones de la cuota y crédito de impuestos. En este último, la transferencia percibida que corresponde al exceso del crédito sobre la cuota se computa como una prestación en metálico.

Como se aprecia de forma nítida en el gráfico anterior, la mayoría de los países de la OCDE gastan más en transferencias económicas para el cuidado infantil, incluido el apoyo a familias monoparentales (monomarentales, en su mayoría), que en servicios sociales, salvo países como Francia, Dinamarca, Islandia, Italia, España, etc. en donde el coste de los servicios sociales supera el de las transferencias. 4

Si se considera el caso de España, destaca la escasa relevancia pública a la atención infantil en comparación con otros países. Aunque, es menester destacar el esfuerzo efectuado durante los últimos años, mejorando la cobertura escolar para menores de tres años, aunque de forma muy diferenciada por Comunidades Autónomas. Debe recordarse que en la Cumbre del Milenio, de Barcelona se estableció como objetivo, para 2010, una tasa de escolarización infantil primaria del 33\%. Si bien, en el curso escolar 2007-2008 seguían apreciándose diferencias muy notables a escala territorial.

\footnotetext{
4 En este estudio de la OCDE, se advierte que los gastos efectuados a escala local pueden quedar distorsionados, como en el caso de los países nórdicos, donde muchos servicios sociales se efectúan a nivel local aunque con transferencias del Gobierno; pero incluso puede no reflejarse adecuadamente la realidad del coste de estas políticas sociales en otros países con estructura federal, como en el caso de Canadá o Suiza
} 
Tasa de escolarización, 2007-2008

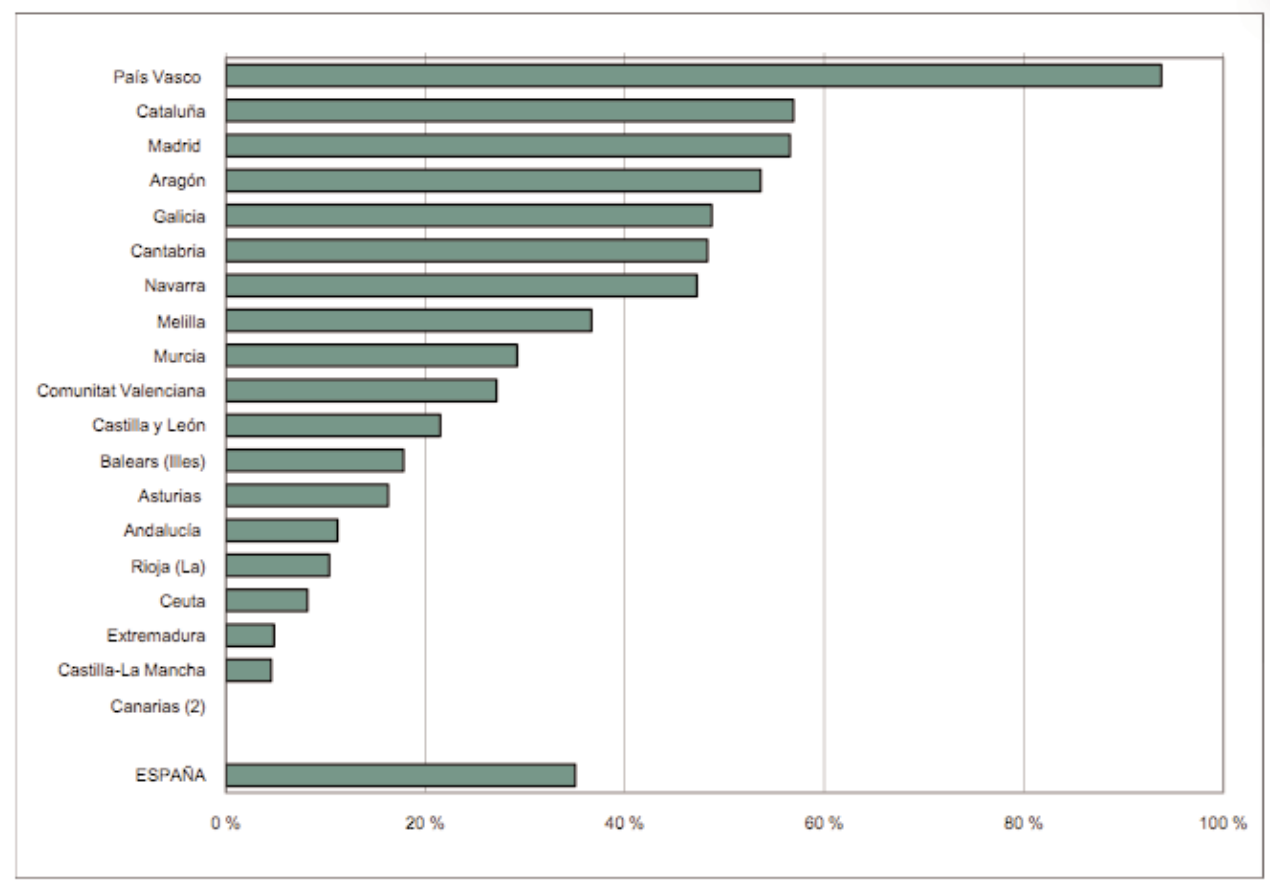

Para el curso escolar 2009- 2010, de acuerdo con el Ministerio de Educación la tasa de escolaridad para España, en centros públicos y privados es la siguiente:

\section{$\underline{1999-2000}$}

Menores de 1 año

1 año

2 años

3 años
$1 ' 5 \%$

$6,8 \%$

$16,0 \%$

$84,3 \%$ $\underline{2009-2010}$

$7^{\prime} 6 \%$

$27^{\prime} 6 \%$

$44^{\prime} 8 \%$

$99^{\prime} 1 \%$

Fuente: Datos y Cifras de Curso Escolar 2011/2012. Ministerio de Educación. Secretaria General Técnica

Los datos de la tabla anterior ponen de manifiesto el cambio favorable en la cobertura educativa y escolarización en los primeros años de la vida. Si bien el incremento de esta oferta educativa se debe tanto al aumento de centros públicos como privados.

El impacto de las transferencias públicas es analizado por Simmonnazzi (2010) y Bettio (2010) y destacan la necesidad de diferenciar de forma nítida cuando se otorgan para el cuidado de personas mayoras o para la atención de niños y niñas. 
En el primer caso la situación puede ser menos grave que en el segundo respecto al empleo femenino en el mercado de trabajo. Ambas autoras afirman que en Alemania, las transferencias públicas han coadyuvado al florecimiento de un sector emergente en el cuidado de personas mayores de carácter formal, mientras que en otros como Italia y España han servido para fortalecer un sector informal de bajos salarios, apoyado en el flujo masivo de inmigrantes, fundamentalmente mujeres, que lo ha nutrido. Quizá estas transferencias puedan servir para resolver de una forma "eficiente", desde una perspectiva económica, al considerar la baja relación de mujeres en el empleo entre los 55-64 años, cuando sus padres necesitan mayor atención y cuidado.

Por consiguiente esta política de transferencias públicas para el cuidado de mayores dependientes puede resultar acorde con los criterios de "racionalidad económica", si se contempla desde la perspectiva del coste de oportunidad o desde el enfoque de conciliación de la vida familiar, profesional y privada de las personas (principalmente mujeres) que en esas cohortes tardías de edad laboral tienen escasa vinculación con el mercado de trabajo.

Ahora bien, estas transferencias para el cuidado de mayores dependientes, apuntalan el modelo de familia tradicional, cuando son los miembros de la propia familia (casi siempre las mujeres) quienes se encargan de los familiares dependientes aunque recibiendo por ello una escasa remuneración económica como ha ocurriendo en España con el desarrollo de la Ley de Autonomía Personal de 2006. Más del $50 \%$ del coste del desarrollo de esta norma se dedicaba a este concepto (Villota, Ferrari y Vázquez, 2011).

En resumen, parece ser que la política de transferencias tiende a consolidar la emergencia del sector informal mediante la inclusión en el mismo de parte del cuidado familiar, como apunta Morel (2007), pues tanto en los países Mediterráneos como en el caso de aquellos que disfrutan de regímenes de Bienestar denominados Bismarkianos, de acuerdo con la tipología establecida por Esping Andersen (1993), se parte de la premisa tendente a consolidar el cuidado domiciliario sobre el institucional, al tiempo que intentan hacer el trabajo de cuidado tradicional más "atractivo" en lugar de ingresar en el mercado de trabajo.

Por otra parte, Simmonnazzi (2008) citando a Lewis et al. (2008) contempla el impacto del cuidado en el empleo femenino haciendo hincapié en la diferencia existente en el destino otorgado a las transferencias pues las propias políticas europeas han diferenciado sus recomendaciones en el cuidado infantil y el de personas mayores, al resaltar la distinta edad en la que uno y otro tiene lugar y, por consiguiente su distinta repercusión en el empleo femenino:

"The trend in favour of home care (away from services), supported by cash transfers in the case of elderly care stands in clear contrast with the EU policy encouraging child care services rather than leaves and setting targets for childcare pro- 
vision. Social considerations (the social investment aspect of child care, on one hand, and the elderly people preference for home care on the other) may have reinforced labour market considerations: the fact that motherhood occurs in the peak of a woman's active life and that child covers several years, while elderly care falls upon women (spouses, daughters) in the latter part of their active life may play a role here”.

Ahora bien, a pesar de los esfuerzos realizados en España durante los últimos años, seguimos presentando un importante déficit de servicios sociales de cuidado que obstaculiza la permanencia femenina en el mercado de trabajo, mientras que las mujeres de países como Italia, Grecia y Portugal, con un modelo social similar no parecen acusar tanto su falta. Los datos ofrecidos por las estadísticas laborales de la UE muestran esta deficiencia y claman por una acción política drástica:

Inactividad y trabajo a tiempo parcial entre las mujeres debido a la falta de servicios de cuidado (\% de la población total femenina con responsabilidades de cuidado), en 2008

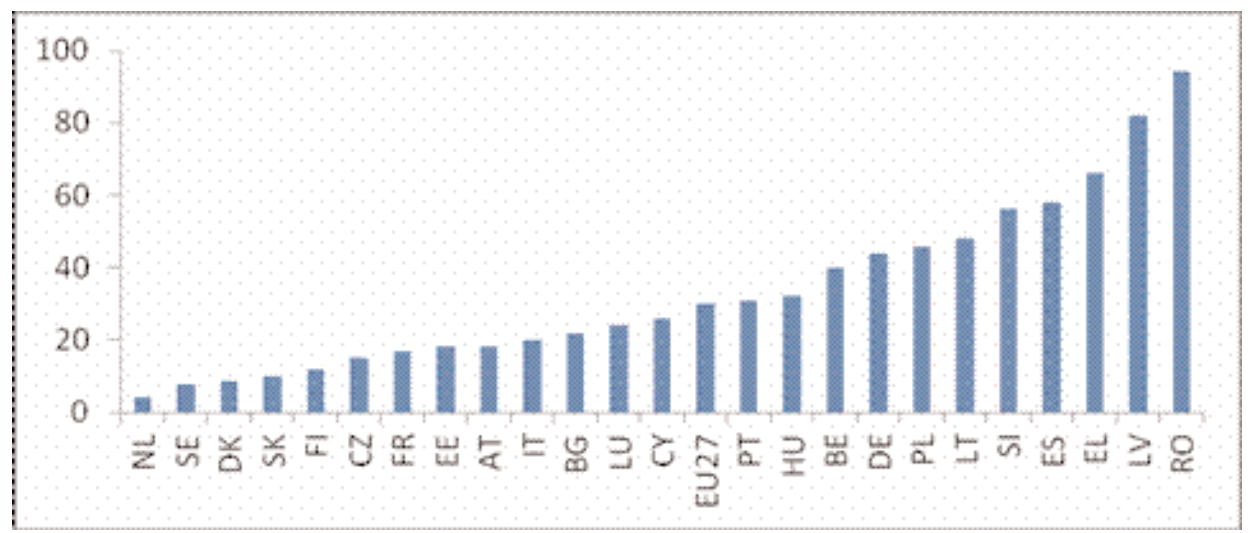

(Fuente: Eurostat - Labour Force Survey. IE, MT, UK: datos no facilitados)

La percepción negativa de la falta de servicios sociales observada por las españolas y la imposibilidad de permanecer en el mercado de trabajo o hacerlo solo con un empleo a tiempo parcial, sitúa a nuestro país en el furgón de cola en la representación gráfica anterior, en comparación con los distintos países de la UE, y debería servir para cambiar el rumbo de nuestra política económica y social para evitar la pervivencia de esta distorsión en el futuro.

Antes de concluir este apartado, me gustaría recordar que el desarrollo de servicios sociales ha permitido en Suecia y otros países nórdicos la permanencia de las mujeres en el mercado de trabajo, aunque de una manera un tanto segmentada: educación pública y privada (sobre todo infantil, preescolar y primaria), sanidad y servicios sociales (públicos y privados). Por ello, se produce una fuerte interrelación entre gasto social público (circunscrito al empleo en educación, sanidad y tra- 
bajo social) y tasa de ocupación de las mujeres. Asa Löfström (2001) ha analizado su existencia, en el ámbito de la OCDE, en los inicios de este siglo y es constatable que esa correlación perdura (Villota y Vázquez, 2009).

Tampoco la presión fiscal del país permanece ajena a este hecho, puesto que suele traducirse en una mayor y mejor oferta de infraestructuras sociales que a su vez se nutren, en la mayoría de los casos, de mano de obra femenina. Por tanto, se puede afirmar que el sector público ha venido cumpliendo una doble función, pues, por una parte, ha prestado los servicios de atención a las personas posibilitando con ello a las mujeres su permanencia en el mercado de trabajo; y, por otra, ha generado para ellas importantes oportunidades de empleo.

Por último, hay que subrayar que la crisis económica actual ha generado una situación de pánico y un viraje brutal de la política económica, con importantes recortes del gasto social, incluyendo el ámbito del cuidado. Por ello, no es de extrañar, que el modelo social se tambalee, con la nueva entrada en recesión de la economía española, en particular, y europea, en general, en el año 2012. Solo una voluntad política y social decidida puede ser capaz de resistir los embates de la recesión económica y proseguir los esfuerzos llevados a cabo desde la Transición para la conservación, e incluso mejora de nuestro modelo social.

\section{A MODO DE CONCLUSIÓN}

En este último apartado, voy a incluir algunos datos de la OCDE, con la intención de llamar la atención sobre la anómala evolución observada en España, durante los últimos años, con una masiva contratación por parte de las familias de personal doméstico, para la realización de las tareas de cuidado. Esta evolución abarca desde los ochenta y muestra, desde 1994 una tendencia ascendente en la contratación de personal doméstico remunerado. Al parecer, se ha ido configurando esta opción como una herramienta estratégica para cubrir la demanda insatisfecha de cuidado infantil y mayores dependientes. Si bien, solamente personas con suficientes medios económicos pueden utilizarla y compatibilizar así su vida profesional, familiar y privada. Por supuesto, la escasez de servicios sociales públicos, para el cuidado y atención de las personas a lo largo del ciclo vital, obliga a recurrir a familiares (abuelas, madres, cónyuges, etc.) y/o, cuando se dispone de renta suficiente, contratar ayuda domiciliaria formal o informal. Por el contrario, esta opción es casi inexistente en otros países europeos con regímenes de Bienestar muy desarrollados, como en el caso del modelo Nórdico, imperante en Suecia, Finlandia, Dinamarca y Noruega, en donde apenas se contrata a personal doméstico. Sin embargo, no se puede obviar el elevado coste económico de estos modelos sociales, solo factible, gracias al esfuerzo económico colectivo llevado a cabo durante muchos años y reflejado en su elevada presión fiscal. 
Al efectuarse en España una contratación de personal doméstico, sobre todo la que tiene lugar desde los primeros años del siglo XXI, se evidencia una clara disimilitud con los restantes países de la UE, en su mayoría con regímenes sociales en los el cuidado de las personas se ha ido consolidando de forma paulatina. Solo Italia, muestra una evolución similar a la nuestra, aunque no tan extrema, mientras que Portugal y Grecia no presentan un comportamiento paralelo, aunque pertenezcan a un modelo social semejante en el diseño de sus políticas sociales familiares, de acuerdo con la clasificación de Gautier (2003).

Sin duda, las transferencias públicas y las deducciones fiscales, imperantes en nuestro régimen fiscal y social han reforzado esta evolución, aunque la falta de espacio me impide detenerme más en este punto. Solamente me quedaría comentar el impacto del proceso de globalización, con una entrada masiva de inmigrantes, facilitando mano de obra barata para llevar a cabo el trabajo de cuidado demandado por las familias. El efecto llamada de este hecho, generado por la demanda familiar de personas dispuestas a llevar a cabo los trabajos de cuidado y la oferta proveniente de países empobrecidos por crisis reincidentes, no suele ser reconocido, mientras que el impacto en la mano de obra inmigrante del "boom" de la construcción se ha barajado extensamente. Solamente los estudios centrados en las cadenas globales del cuidado han enfocado certeramente este fenómeno.

Hogares que emplean personal doméstico y empleados/as trabajando en hogares, EU15 (1988-2007)

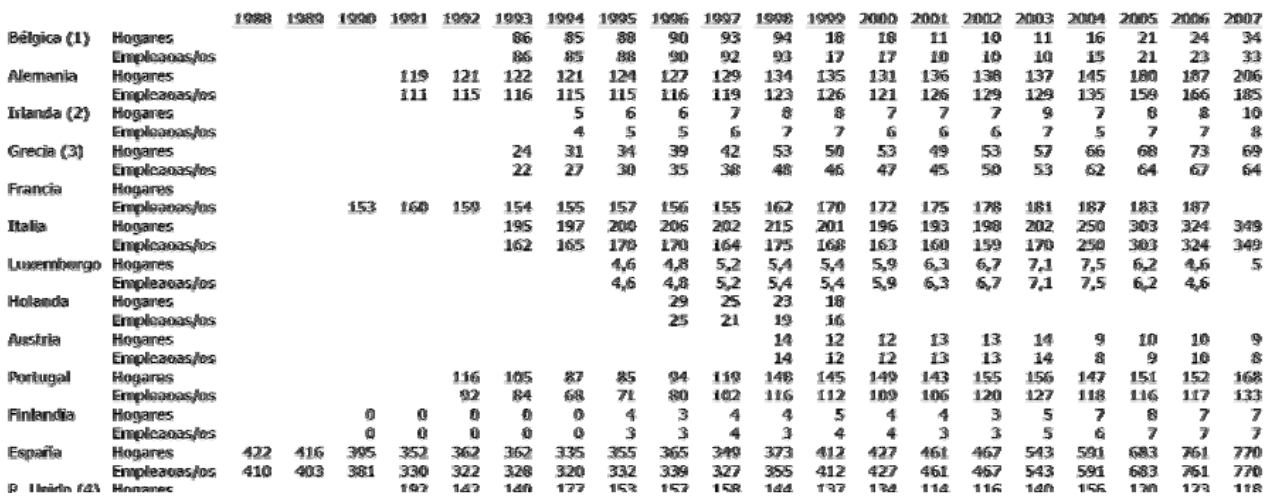


Evolución de los hogares que emplean personal doméstico

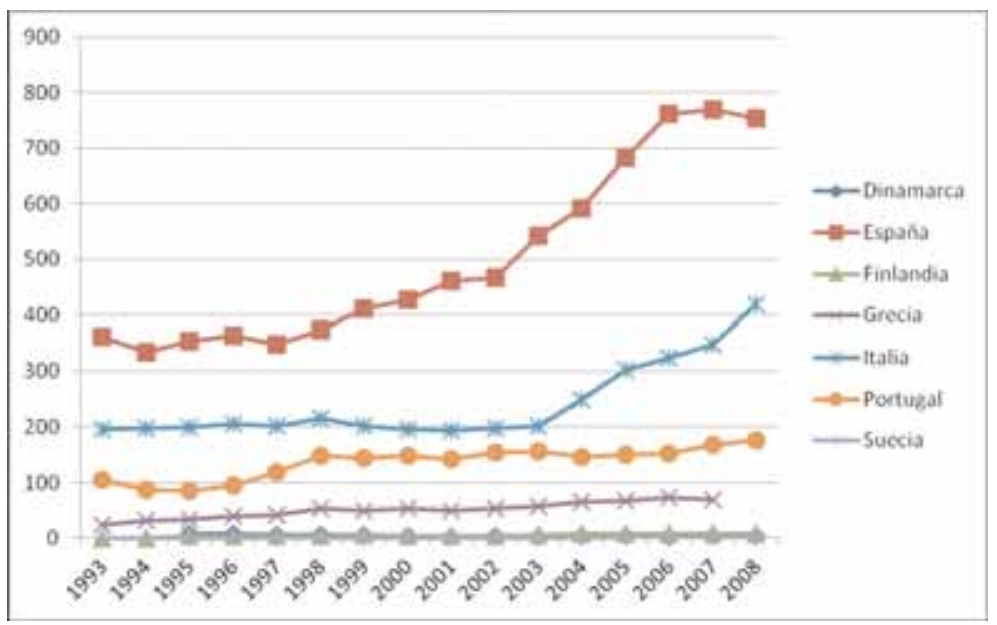

(Fuente: elaboración propia a partir de OECD Labour Force Statistics 1987-2008, Paris, 2009)

Por otra parte, resulta encomiable el esfuerzo efectuado para la ampliación del modelo social durante los últimos años, con la inclusión del cuidado de la dependencia de personas mayores y la educación infantil para menores de tres años. Si bien, este modelo social siendo todavía una obra inacabada, está siendo erosionada y puesto en cuestión por la crisis económica actual, con su impacto en la brusca caída de la recaudación (que hemos visto) y consiguiente pérdida de recursos económicos. Lo que puede hacer tambalearse la totalidad de sus cimientos y poner en duda su permanencia, como apunta Ignacio Sotelo en la cita con la que inicié este artículo, al conjeturar que solo "una caída en picado de la economía“ podría arriesgar su pervivencia.

\section{BIBLIOGRAFIA}

BETTIO, F. and SOLINAS, G. (2009), 'Which European Model for Elderly Care? Equity and Cost-Effectiveness in Home Based Care” in Three European Countries', Economia \& Lavoro 43:1, 53-71.

BETTIO, F., A. SIMONAZZI and P. VILLA (2006) 'Change in care regimes and female migration: the care drain in the Mediterranean', Journal of European Social Policy 16:3, 271-285.

BETTIO, F. and A. VERASHCHAGINA (eds) (2008), Frontiers in the Economics of Gender (London:

Routledge). http://ec.europa.eu/employment_social/news/2008/apr/long_term_care_en.pdf

EC (2007), Health and long-term care in the European Union, Special Eurobarometer, December, http://ec.europa.eu/public opinion/archives/ebs/ebs 283 en.pdf 
EC (2008) 'Long-term care in the European Union', DG Employment, Social Affairs and Equal Opportunities Luxembourg: European Communities.

EC (2008) Employment in Europe. Luxembourg: European Communities.

ESPING-ANDERSEN, Gosta (1990): The Three Worlds of Welfare Capitalism, Cambridge, Polity Press,

EUROSTAT EU Labour Force Survey. Luxembourg

EUROSTAT Living Conditions in Europe. Luxembourg

FERRERA, M. (1995), “Los Estados del Bienestar del Sur en la Europa Social” in Sarasa, S. y MORENO, L. El Estado del Bienestar en la Europa del SUR. CSIC y Ministerio de Asuntos Sociales.

FERRERA, M. (1996), “The Southern Model of Welfare in Social Europe”. Yournal of European Social Policy num. 6(1), p. 17-37.

GAUTHIER, A. H. (2002) "Les politiques familialesdans les pays industrialises. Y a-til convergence?”. Revue Population-F, 457-484

KNIN, T. (2004): "Family Solidarity and Social Solidarity: Substitutes or Complementers ? en Knin T. y Komter, A (eds.) Solidarity Betwenn the Sexes and the Generations. Chletelham/Norsthampton: Edward Elgar , pp18-33

KNIN,T y KOMTER, A (eds.) Solidarity Betwenn the Sexes and the Generations. Chletelham/Norsthampton: Edward Elgar

LEWIS, J. CAMPBELL, M., HUERTA, C. (2008), 'Patterns of paid and unpaid work in Western Europe: gender, commodification, preferences and the implications for policy’, Journal of European Social Policy, 18:1, 21-37.

LÖFSTRÖM, Ä. (2001): A report on gender equality and economic growth. www.testh2.scb.se/tus/tus

MINISTERIO DE EDUCACIÓN: Datos y Cifras .Curso Escolar 2011-2012. Secretaría General Técnica. 2011.

MOREL, N. (2007) 'Care policies as employment strategy. The impact of Bismarckian welfare state institutions on child- and elderly-care policy reforms in France, Belgium, Germany and the Netherlands' (mimeo).

OECD (2005) Trends in International Migration, SOPEMI Report Paris: OECD).

OECD (2011) Revenue Statistics 1965-2010

OECD: Social Expenditure Database. www.oecd.org/els/social/expenditure

PINNELLI, A., RACCIOPPI, F. y TERZERA, L. (2007), Genere, Famiglia e Salute, Milano: Franco Angeli.

RODRIGUEZ CABRERO, G (1991) Estado, Privatización y Bienestar. Un debate de la Europa actual. FUHEM-Icaria, Madrid-Barcelona

SIMONAZZI, A. (2006b), The elderly care sector in Italy, EU Project 'Dynamo' (Dynamics of

National Employment Models), $6^{\text {th }}$ Framework Programme.

SIMONAZZI, A. (2009), 'Care Regimes and national employment models', Cambridge Journal of Economics, 33:2, 211-32.

SIMONAZZI, A. (2011) "Home Care and Cash Transfers: The Search for a Sustainable Elderly Care Madel” en Addis et al. Gender and Well-Being. The Role of Institutions. Ashgate, London

SOTELO, Ignacio (2010): El Estado Social. Antecedentes, origen, desarrollo y declive. Editorial Trotta 
UNGERSON, C. and YEANDLE, S. (eds) (2007), Cash for Care In Developed Welfare States (Basingstoke: Palgrave, Macmillan).

VILLOTA, P. and VÁZQUEZ, S. (2009): “The welfare state in Spain: unfinished business” en SHUBERT, K. et al. (editors) The Handbook of European Welfare Systems. Routledge.

VILLOTA, P. (2010) “Interrelación entre la oferta laboral femenina y la presión fiscal” en Mujeres, Género, Economía, Valor en alza. NOSDO, Ayuntamiento de Sevilla, pp. 58-69.

VILLOTA, P., FERRARI, I. y VÁZQUEZ, S. (2011), Impacto de la crisis económica en el trabajo doméstico remunerado domiciliario y propuesta de medidas de política fiscal, social y laboral para estimular su formalización y profesionalización. Instituto de la Mujer, Fondo Social Europeo. 
Anexo

\begin{tabular}{|c|c|c|c|c|c|c|c|c|c|}
\hline & 1975 & 1985 & 1995 & 2005 & 2006 & 2007 & 2008 & 2009 & $\underline{2010}$ \\
\hline Australia & $\overline{25,1}$ & $\overline{27,5}$ & $\overline{28,1}$ & $\overline{29,8}$ & $\overline{29,3}$ & $\overline{29,4}$ & $\overline{27,0}$ & $\overline{25,9}$ & \\
\hline Alemania & 34,3 & 36,1 & 37,2 & 35,0 & 35,6 & 36,0 & 36,4 & 37,3 & 36 , \\
\hline Austria & 36,6 & 40,8 & 41,4 & 42,1 & 41,5 & 41,8 & 42,8 & 42,7 & 20 \\
\hline Bélgica & 39,5 & 44,3 & 43,5 & 44,6 & 44,2 & 43,6 & 44,1 & 43,2 & \\
\hline Canada & 32,0 & 32,5 & 35,6 & 33,4 & 33,3 & 33,0 & 32,2 & 32,0 & , 0 \\
\hline Chequia &. & & 37,6 & 37,5 & 37,0 & 37,3 & 36,0 & 34,7 & \\
\hline Chile & .. & .. & 19,0 & 21,6 & 23,2 & 24,0 & 22,5 & 18,4 & 0,9 \\
\hline Corea & 14,9 & 16,1 & 20,0 & 24,0 & 25,0 & 26,5 & 26,5 & 25,5 & 5,1 \\
\hline Dinamarca & 38,4 & 46,1 & 48,8 & 50,8 & 49,6 & 48,9 & 48,1 & 48,1 & 8,2 \\
\hline EEUU & 25,6 & 25,6 & 27,8 & 27,1 & 27,9 & 27,9 & 26,3 & 24,1 & 1,8 \\
\hline España & 18,4 & 27,6 & 32,1 & 35,7 & 36,6 & 37,2 & 33,3 & 30,6 & 1,7 \\
\hline Estonia & & & 36,3 & 30,6 & 30,7 & 31,4 & 31,7 & 35,9 & 4,0 \\
\hline nlandia & 36,6 & 39,8 & 45,7 & 43,9 & 43,8 & 43,0 & 42,9 & 42,6 & 2,1 \\
\hline ancia & 35,5 & 42,8 & 42,9 & 44,1 & 44,4 & 43,7 & 43,5 & 42,4 & 2,9 \\
\hline reci & 19,4 & 25,5 & 28,9 & 31,9 & 31,2 & 31,8 & 31,5 & 30,0 & 0,9 \\
\hline oland & 40,7 & 42,4 & 41,5 & 38,4 & 39,1 & 38,7 & 39,1 & 38,2 & \\
\hline Hungria & , & .. & 41,5 & 37,3 & 37,3 & 40,3 & 40,1 & 39,9 & 37,6 \\
\hline Irlanda & 28,7 & 34,6 & 32,5 & 30,3 & 31,7 & 31,0 & 29,1 & 27,8 & 28,0 \\
\hline Islandia & 30,0 & 28,2 & 31,2 & 40,7 & 41,5 & 40,6 & 36,7 & 33,9 & 36,3 \\
\hline rael & . & .. & 37,0 & 35,6 & 36,0 & 36,3 & 33,8 & 31,4 & 32,4 \\
\hline alia & 25,4 & 33,6 & 40,1 & 40,8 & 42,3 & 43,4 & 43,3 & 43,4 & 43,0 \\
\hline Japon & 20,7 & 27,1 & 26,8 & 27,4 & 28,0 & 28,3 & 28,3 & 26,9 & \\
\hline Luxemburgo & 32,8 & 39,5 & 37,1 & 37,6 & 35,9 & 35,6 & 35,5 & 37,6 & 36,7 \\
\hline Mexico & .. & 15,5 & 15,2 & 18,1 & 18,2 & 17,7 & 20,9 & 17,4 & 18,1 \\
\hline N. Zelanda & 28,4 & 30,9 & 36,2 & 36,7 & 36,0 & 34,9 & 33,6 & 31,5 & 31,3 \\
\hline Noruega & 39,2 & 42,6 & 40,9 & 43,5 & 43,9 & 43,6 & 42,9 & 42,9 & 42,8 \\
\hline Polonia & & & 36,2 & 33,0 & 34,0 & 34,8 & 34,2 & 31,8 & \\
\hline Portugal & 19,1 & 24,5 & 29,3 & 31,2 & 31,9 & 32,5 & 32,5 & 30,6 & 31,3 \\
\hline 2. Unido & 34,9 & 37,0 & 34,0 & 35,7 & 36,4 & 36,0 & 35,7 & 34,3 & 35,0 \\
\hline Slovaquia &.. &.. & 40,3 & 31,5 & 29,4 & 29,4 & 29,4 & 29,0 & 28,4 \\
\hline Slovenia & .. & .. & 39,0 & 38,6 & 38,3 & 37,7 & 37,0 & 37,4 & 37,7 \\
\hline uecia & 41,3 & 47,4 & 47,5 & 48,9 & 48,3 & 47,4 & 46,4 & 46,7 & 5,8 \\
\hline uiza & 24,4 & 25,8 & 27,7 & 29,2 & 29,1 & 28,9 & 29,1 & 29,7 & 29,8 \\
\hline Turquia & 11,9 & 11,5 & 16,8 & 24.3 & 24,5 & 24.1 & 24,2 & 24,6 & 26,0 \\
\hline
\end{tabular}

(Fuente: Revenue Statistics 1965-2010. OECD, Paris 2011) 